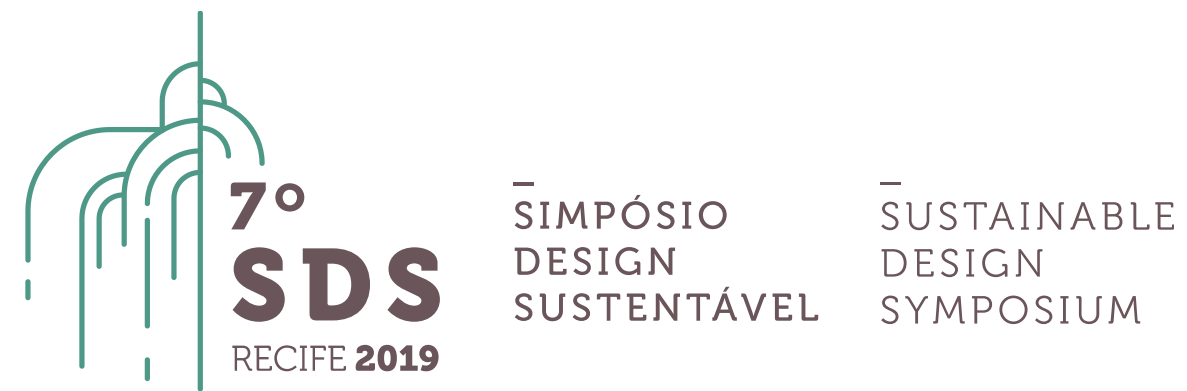

\title{
Aplicação da Abordagem Sistêmica no Âmbito de um Empreendimento Existente: Workshop Design Sistêmico Loading... A Construção de um Modelo Econômico-produtivo Sustentável
}

\author{
Rodrigo Braga França ${ }^{1}$, Thais Helena Behar Alem², Kátia Andréa Carvalhaes Pêgo ${ }^{3}$ \\ ${ }^{1}$ Universidade do Estado de Minas Gerais, Mestrando, rodrigobragafranca@gmail.com \\ 2Universidade do Estado de Minas Gerais, Mestranda, thaisbehar1@gmail.com \\ ${ }^{3}$ Universidade do Estado de Minas Gerais, Profa. Dra . Departamento de Planejamento e Configuração, \\ katia.pego@uemg.br
}

\begin{abstract}
Resumo. Esse artigo tem como objetivo apresentar uma experiência de aplicação da metodologia Design Sistêmico, a partir da análise de um empreendimento real e a transformação do local por meio dessa abordagem. Tal atividade ocorreu por meio do workshop 'Design Sistêmico Loading... a construção de um modelo econômico-produtivo sustentável'. Primeiramente, apresentamos algumas considerações teóricas acerca da metodologia e seu propício emprego no contexto contemporâneo. Em seguida descrevemos a atividade realizada durante os cinco dias de imersão, no qual se analisou o empreendimento 'Mercado da Boca', localizado na Região Metropolitana de Belo Horizonte - MG, assim como as características socioeconômicas e culturais da região. Como resultados, exibimos a síntese dessa análise, por meio do Relevo Holístico, e o subsequente projeto sistêmico, por intermédio do Mapa Iconográfico. Concluímos que com a aplicação da abordagem sistêmica é possível reequilibrar a relação entre produção, ambiente e sociedade, gerando resultados positivos em nível econômico, social, ambiental e cultural do território em questão.
\end{abstract}

Palavras-chave. Design Sistêmico. Desenvolvimento de Negócios. Economia Local. Sustentabilidade. Valorização do Território. Cultura.

\section{Introdução}

Desde a revolução industrial o modelo econômico baseado na produção em massa tem fomentado um padrão de consumo contínuo e crescente na sociedade. Os ideais modernistas, com crença em um crescimento ilimitado, tinham como base uma economia de escala que, com suas eficientes linhas de montagens, seriam a garantia ao atendimento às necessidades humanas e de progresso contínuo, por meio da racionalização da produção e promoção do consumo.

Apesar dos inegáveis avanços tecnológicos, científicos e, mais recentemente, da introdução 
de outros meios de desenvolvimento econômico - como a ascensão do mercado de serviços Imbesi (2012) ressalta as consequências negativas desse padrão de produção e consumo, evidenciadas pela globalização, quais sejam: escassez de recursos, poluição, desemprego, desigualdades sociais, saturação de mercados e crises financeiras.

Para Capra e Luisi (2014), a principal característica da maioria dos modelos econômicos contemporâneos é a sua suposição de que o crescimento econômico infinito é possível em um planeta finito. Para os mesmos, esta ilusão "[...] é o dilema fundamental presente nas raízes de todos os principais problemas da nossa época" (CAPRA; LUISI, 2014, p. 85). O economista Tim Jackson afirma que a estabilidade do nosso modelo econômico depende do consumo contínuo e crescente, contudo, lembra que o planeta não comporta mais crescimento, pelo menos não como se praticou até hoje ${ }^{1}$.

Bistagnino (2011) atribui ao emprego desse modelo de produção e consumo como um dos principais responsáveis pelas crises contemporâneas nos campos social, cultural, ambiental e econômico. Para o autor, tais crises ocorrem, principalmente, devido ao fato de estarmos aplicando, até hoje, conceitos de uma visão arcaica do mundo, sob o manto do mecanicismo ${ }^{2}$ da ciência cartesiana-newtoniana, ou seja, no paradigma que valoriza a ciência da quantidade (linear) em detrimento da ciência da qualidade (não linear - sistêmica ou holística ${ }^{3}$ ). $O$ autor acrescenta ainda, que o modelo atual não funciona porque não é capaz de se sustentar em médio e longo prazos. Neste contexto, destaca-se que o próprio conceito de 'Desenvolvimento Sustentável' ${ }^{4}$ é impregnado de longevidade. Lembramos que uma das maiores contribuições de sua definição foi a capacidade de afastar os conceitos de "crescimento econômico" e de "desenvolvimento", antes considerados inseparáveis.

Interessante destacar que na obra 'O Ponto de Mutação', publicada em 1982, Capra já havia alertado para a necessidade e urgência de um redirecionamento comportamental para a sociedade, para os indivíduos e para as organizações, baseado no 'pensamento sistêmico' e nas estruturas de 'redes' ${ }^{\prime}$. O autor esclarece que o 'pensamento sistêmico' consiste em uma mudança de paradigma, na qual as partes não são mais vistas nem analisadas separadamente, mas sempre fazendo parte de um todo. Nele, os elementos de um sistema ${ }^{6}$ são assistidos na forma de relacionamentos coordenados, no qual se deve observar sob todas as direções através do fluxo de ligações entre os elementos deste sistema. Sendo assim, o pensamento sistêmico concentra-se não em blocos de construção básicos, mas em princípios de organização básicos. O pensamento sistêmico é

\footnotetext{
1 Entrevista à Folha de São Paulo após participação de um evento paralelo à Rio+20. Disponível em: <http://www1.folha.uol.com.br/fsp/cotidiano/49945-crise-prova-que-atual-modelo-economico-e-inviavel.shtml>. Acesso em: 08 jan. 2019.

${ }^{2}$ Sumariamente, podemos descrever o pensamento mecanicista como racional, composto por cadeiras lineares de causa e efeito, na qual a ciência é sinônimo de matemática, tem como base o método analítico, e o mundo é visto como uma máquina perfeita, é um pensamento de estruturas.

${ }^{3} \mathrm{Na}$ visão holística, pondera-se o mundo como um todo indivisível e intrinsicamente dinâmico, considera-se o contexto e as relações, é um pensamento de processo (pensamento processual, no qual toda estrutura observada é entendida como a manifestação dos processos subjacentes). Neste contexto, o todo é considerado como mais do que a soma de suas partes.

${ }^{4}$ Desenvolvimento Sustentável foi definido como aquele que "[...] atende às necessidades do presente sem comprometer a possibilidade de as gerações futuras atenderem as suas próprias necessidades" (COMISSÃO MUNDIAL SOBRE O MEIO AMBIENTE E DESENVOLVIMENTO, 1988, p. 46).

5 "'Rede' significa uma forma de organização não-linear dos componentes de um sistema, que se influenciam reciprocamente por meio de diversos 'caminhos', e não segundo uma linha casual única e exclusiva" (CAPRA, 2002, p. 13). Em uma de suas obras mais conhecidas 'A teia da vida' (publicada em 1996), o autor reuniu múltiplas contribuições da física, da biologia e da matemática para a compreensão dos sistemas vivos, especialmente seu padrão de organização. Nesta, a 'rede' é identificada como esse 'padrão' comum a todos os organismos vivos, "[...] onde quer que encontremos sistemas vivos - organismos, partes de organismos ou comunidades de organismos - podemos observar que seus componentes estão arranjados à maneira de rede. Sempre que olhamos para a vida, olhamos para redes. [...] O padrão da vida, poderíamos dizer, é um padrão de rede capaz de auto-organização" (significa que seu comportamento é estabelecido pelo próprio sistema, e não imposto pelo ambiente) (CAPRA, 2012, p. 67).

6 'Sistema' é um conjunto articulado de elementos organizados de um determinado modo que atinja um objetivo. Este é composto de três tipos de especificidades: elementos, interconexões e finalidade ou função (CAPRA; LUISI, 2014).
} 
'contextual' ${ }^{7}$, oposto ao pensamento analítico ${ }^{8}$ (CAPRA, 2012). Segundo o mesmo, é a abundância de caminhos possíveis que torna a 'rede' uma terra fecunda e apropriada para a inovação. Capra e Luisi (2014) destacam que o 'pensamento sistêmico' se processa por meio de relações, contextos e padrões.

Nessa conjuntura, Bistagnino (2009) alerta que já não é possível afrontar as crises contemporâneas com antigas soluções baseadas no pensamento reducionista-mecanicista, pois os problemas atuais são sistêmicos, i.e., estão intimamente interligados e são interdependentes. Ele reitera que é preciso considerar novos contextos de desenvolvimento por meio da ótica alargada do 'sistema', que é constituído pelas conexões entre seus elementos ou componentes, gerando uma 'rede'.

Moraes (2008) demonstra que, o outrora cenário 'estático', de progresso linear e previsível, foi substituído por um quadro cada vez mais complexo ${ }^{9}$, fluído e dinâmico, de difícil compreensão que, segundo o autor, "[...] tende a tensões contraditórias e imprevisíveis e, através de bruscas transformações, impõe contínuas adaptações e reorganização do sistema” (MORAES, 2008, p.7). 0 cenário de crise denota um ambiente de complexidade, próprio da contemporaneidade.

\section{Design Sistêmico}

No âmbito do design, diversos profissionais, teóricos e pesquisadores como Branzi (2006), Moraes (2008), Krucken (2008), Thackara (2008), Vieira (2009), Celaschi e Formia (2010), Vassão (2010), Bicocca (2012), Gallio e Marchiò (2012), Irwin (2015), Cardoso (2016), Barauna e Razera (2018), corroboram que o desafio do designer na atualidade é desenvolver e/ou suportar o desenvolvimento de soluções em cenários dinâmicos e de alta complexidade, que já não permitem uma atuação tecnicista e linear, exigindo uma visão alargada de projeto. Isto certamente gera um fluxo de informações não triviais de se investigar e requer tempo, pois estamos lidando com um sistema complexo.

Nesta perspectiva, Manzini e Meroni chamam a atenção para duas questões fundamentais: o tempo e o papel do designer. A primeira é abordada quando afirmam que a qualidade "[...] requer tempo para ser produzida e apreciada", ou seja, é preciso "[...] lentificar (sic) os tempos e os modos nos quais nos relacionamos com as pessoas, os lugares e os bens" (MANZINI; MERONI, In: KRUCKEN, 2009 , p. 15). A segunda questão completa o raciocínio da primeira, pois os autores defendem que, neste âmbito, os designers são os profissionais mais qualificados para atuar, pois a eles é solicitado que imagine cenários e os traduza em produtos e serviços desejáveis. Estes devem se caracterizar pela relação com o território e com sua comunidade, estimulando o reconhecimento de sua identidade. Esse campo deve então, ser o resultado da atividade de uma 'rede' de sistemas locais que possuem uma identidade única, uma dimensão global e uma viabilidade econômico-produtiva.

Contudo, para atuar efetivamente nesse contexto não havia, até então, uma metodologia de projeto que considerasse tal complexidade. Sendo assim, o professor Luigi Bistagnino buscou em outros campos do conhecimento a fundamentação teórica para estruturar sua proposta metodológica, quais sejam: i) teoria geral dos sistemas $^{10}$; ii) teoria especial da relatividade ${ }^{11}$; iii)

\footnotetext{
${ }^{7}$ Ao invés de reduzir o foco à procura de partes elementares, o pensamento sistêmico procura contextualizar o fenômeno a ser investigado, identificando o todo que contém a parte (ou subsistema, ou objeto) em questão.

${ }^{8} \mathrm{Na}$ análise, desmembra-se o fenômeno a ser compreendido, explica-se as partes isolando-as do seu contexto.

9 Segundo Morin (2005), "[...] a complexidade é um tecido (complexus: o que é tecido junto) de constituintes heterogêneos inseparavelmente associados [...]" e que, efetivamente, ela é "[...] o tecido de acontecimentos, ações, interações, retroações, determinações, acasos, que constituem nosso mundo fenomênico" (MORIN, 2005, p. 13).

${ }^{10}$ Teoria geral dos sistemas - Ludwig von Bertalanffy.

11 Teoria especial da relatividade - Albert Einstein.
} 
teoria da complexidade ${ }^{12}$; iv) teoria quântica ${ }^{13}$; v) teoria dos sistemas ${ }^{14}$; além da blue economy ${ }^{15}$. Tal metodologia, por estar estritamente ligada ao pensamento holístico ${ }^{16}$, foi denominada Design Sistêmico. Seu objetivo é reequilibrar a relação entre produção, ambiente e sociedade, por meio do projeto de fluxos de matéria e energia entre as atividades produtivas de um determinado território.

Ao se projetar um sistema com tal abordagem, destaca-se que tanto os resíduos quanto as emissões tenderão a zero ${ }^{17}$, uma vez que o processo, grosso modo, é a transformação de todos os output (saídas ou 'resíduos') de uma atividade produtiva em input (entrada ou recursos) para outra(s) atividade(s) produtiva(s), preferencialmente, no mesmo território. Interessante notar que o processo metodológico 'imita' o modus operandi da natureza, lembrando que nessa não existe resíduo, pois seus substratos (output, saídas ou ainda 'resíduos') sempre são empregados em outro sistema, em um ou mais dos seus cinco reinos ${ }^{18}$. Em outros termos, os 'resíduos' são considerados como elementos dinâmicos em seus processos, visto que os mesmos são empregados como matéria-prima no contexto onde se insere. Nas palavras de Pauli,

$\mathrm{Na}$ natureza não há resíduos nem desempregados. Todos desempenham um papel, e os restos de um se tornam matéria prima para o outro, em um sistema em 'cascata', no qual nada é desperdiçado. [...] os resíduos de alguns são alimentos para outros (PAULI, 2010, p. 41).

Segundo Bistagnino (2011) a metodologia do Design Sistêmico viabiliza, por meio do aproveitamento positivo dos recursos, a emersão de uma rede de novas relações e de um macro sistema autopoiético ${ }^{19}$ composto por todos os micro sistemas territoriais locais, que conduzem a mudança positiva do ambiente e do território. Como resultado, um novo modelo econômicoprodutivo é gerado, capaz de se sustentar por longos períodos. Nesse modelo, as várias atividades de vida e de produção coexistem de maneira participativa e têm a sua função essencial no sistema, nenhuma prevalece sobre a outra, mas cada uma existe graças a todas as outras. Sendo assim, todos os materiais têm valor, todos os sistemas são importantes e fortemente inter-relacionados, assim como uma rede: é no conjunto de todos os nós que residem sua força e eficácia.

A metodologia do Design Sistêmico é dividida em quatro etapas, quais sejam: 1a) compreensão do território - contextualiza os objetos no território e nos sistemas produtivos em questão, gerando o Relevo Holístico; 2a) sistematização e análise dos sistemas produtivos existentes no território - investiga todos os input e output das atividades (sistemas produtivos) do local; 3a) projeto dos fluxos de matéria e energia entre os sistemas produtivos do território - estabelece de uma 'rede' de relações entre os mesmos; 4aㅗ confronto - confronta a abordagem atual (existente) com a sistêmica (proposta), com o intuito de esclarecer o funcionamento da 'rede' projetada para quem efetivamente vai aplica-la, ou seja, as pessoas dessa comunidade. Majoritariamente, tal processo aumenta exponencialmente a capacidade produtiva do território em questão e,

\footnotetext{
12 Teoria da complexidade - Edgar Morin.

${ }^{13}$ Teoria quântica - físicos, como Planck, Bohr, Heisenberg e Einstein.

${ }^{14}$ Teoria dos sistemas - Fritjof Capra.

${ }^{15}$ Blue economy - Gunter Pauli.

${ }^{16}$ No pensamento holístico (ou sistêmico), pondera-se o mundo como um todo indivisível e intrinsicamente dinâmico, considera-se o contexto e as relações, é um pensamento de processo (pensamento processual, no qual toda estrutura observada é entendida como a manifestação dos processos subjacentes). Neste contexto, o todo é considerado como mais do que a soma de suas partes.

17 Segundo Di Salvo, apud Bistagnino (2011), emissão zero é entendida como eliminação de todas as emissões, sejam eles em estado líquido, sólido ou gasoso.

18 Cinco reinos: plantas, fungos, animais, protista e monera.

${ }^{19}$ Segundo Campagnaro, apud Bistagnino (2011), autopoiese é a propriedade que todos os sistemas vivos têm de auto organizar-se e redefinir-se continuamente de acordo com as relações (a organização do sistema) que existem entre os elementos que o compõem (a estrutura do sistema) e com base na reciprocidade que regem a relação com o seu ambiente. Um sistema autopoiético é aberto ao contexto, o seu valor é maior que a soma das contribuições individuais. Os objetivos (de equilíbrio ou de evolução da qual tende) serão aplicáveis a todos os componentes. Estes últimos são mutuamente interdependentes, assim como todas as estratégias necessárias para a gestão dos fluxos de matéria e energia, na entrada e na saída, os processos de produção e a transformação endógena.
} 
consequentemente, a oferta de postos de trabalho para a população local, trazendo uma perspectiva de cenários eficientes, sustentáveis, saudáveis e duráveis.

Sendo assim, consideramos o Design Sistêmico uma abordagem compatível com os desafios contemporâneos, assim como uma metodologia de desenvolvimento de negócios inovadores sob uma ótica humanista, capaz de gerar novas atividades, produtos, processos e sistemas produtivos, por meio da valorização dos atores, de suas expertises e dos recursos locais.

\section{Metodologia}

A metodologia utilizada para desenvolvimento deste artigo está relacionada com a metodologia empregada na disciplina 'Tópicos Especiais: Design Sistêmico' do Programa de PósGraduação em Design (PPGD) da Universidade do Estado de Minas Gerais (UEMG), perfazendo um total de 70 horas.

A primeira etapa da disciplina foi a explanação das bases teóricas do Design Sistêmico (supracitadas no item 2 desse artigo), sua metodologia e estudo de caso. Ainda em sala de aula, os estudantes iniciaram a construção do Relevo Holístico (ou Mapeamento Geoiconográfico) do território previamente definido (área ocupada por um raio de $30 \mathrm{~km}$ a partir do empreendimento 'Mercado da Boca' (MB), localizado na cidade de Nova Lima - Minas Gerais) com o intuito de compreender o território de maneira holística. Para tanto, foram identificados os aspectos geomorfológicos, a arquitetura, os recursos primários, as redes de abastecimento, a culinária, a oferta de produtos, o artesanato, o folclore e os eventos tradicionais locais.

A partir da compreensão do território, iniciou-se a atividade prática, qual seja, o workshop 'Design Sistêmico Loading - A construção de um modelo econômico-produtivo sustentável'. Tal atividade, desenvolvida ao longo de uma semana (35 horas), fundamentou a discussão deste artigo.

\section{Discussão}

\subsection{Design Sistêmico Aplicado ao Negócio - Experiência Teórica em um Contexto Real}

O workshop 'Design Sistêmico Loading - A construção de um modelo econômico-produtivo sustentável' ocorreu em função da aprovação de um projeto no âmbito do Programa de Apoio a Eventos no País - PAEP | CAPES, realizado pela Universidade do Estado de Minas Gerais (UEMG), Universidade do Vale do Rio dos Sinos (UNISINOS), Universidade Federal de Minas Gerais (UFMG) e pela Systemic Approach Foundation, com edições realizadas nas cidades de Porto Alegre - RS e Belo Horizonte-MG. A atividade foi coordenada pela professora da disciplina de mestrado supracitada - Kátia Andréa Carvalhaes Pêgo, pelo professor do Politecnico di Torino (POLITO) e autor da metodologia - Luigi Bistagnino e pelo professor da Universidade Federal de Juiz de Fora (UFJF) Paulo Miranda, com o auxílio do designer Pedro Henrique Nascimento. O workshop iniciou com a definição do território a ser aprofundado: o MB e seu entorno. A proposta da atividade se deu por meio da análise e síntese do empreendimento e suas relações com o território no estado atual (abordagem linear) para, a partir desta, projetar fluxos de matéria e energia entre os sistemas produtivos do território (abordagem sistêmica). Para a realização do trabalho, os participantes foram divididos em quatro grupos/sistemas: 1) negócio 'Mercado da Boca'; 2) sistema-produto 'cerveja artesanal'; 3) negócio 'Marché'; 4) negócio 'Roça Capital'. Neste artigo, apresentamos o trabalho realizado pelo grupo/sistema negócio MB.

\subsection{Relevo Holístico}

A atividade iniciou com a apresentação, pelos participantes, do Relevo Holístico desenvolvido em sala de aula, com o intuito de reconhecer e sistematizar as características 
peculiares do território em questão ${ }^{20}$.

O resultado se configura como uma representação imagética dos aspectos geomorfológicos, da arquitetura, dos recursos primários, da culinária, do artesanato, do folclore e eventos locais, assim como de boas práticas que ocorrem no território, composto pelas cidades supracitadas, qual seja: o Relevo Holístico (FIGURA 1). Além de ressaltar as características do território, o mesmo facilita o nivelamento das informações e as reflexões sobre o território.

Figura 1 - Relevo Holístico
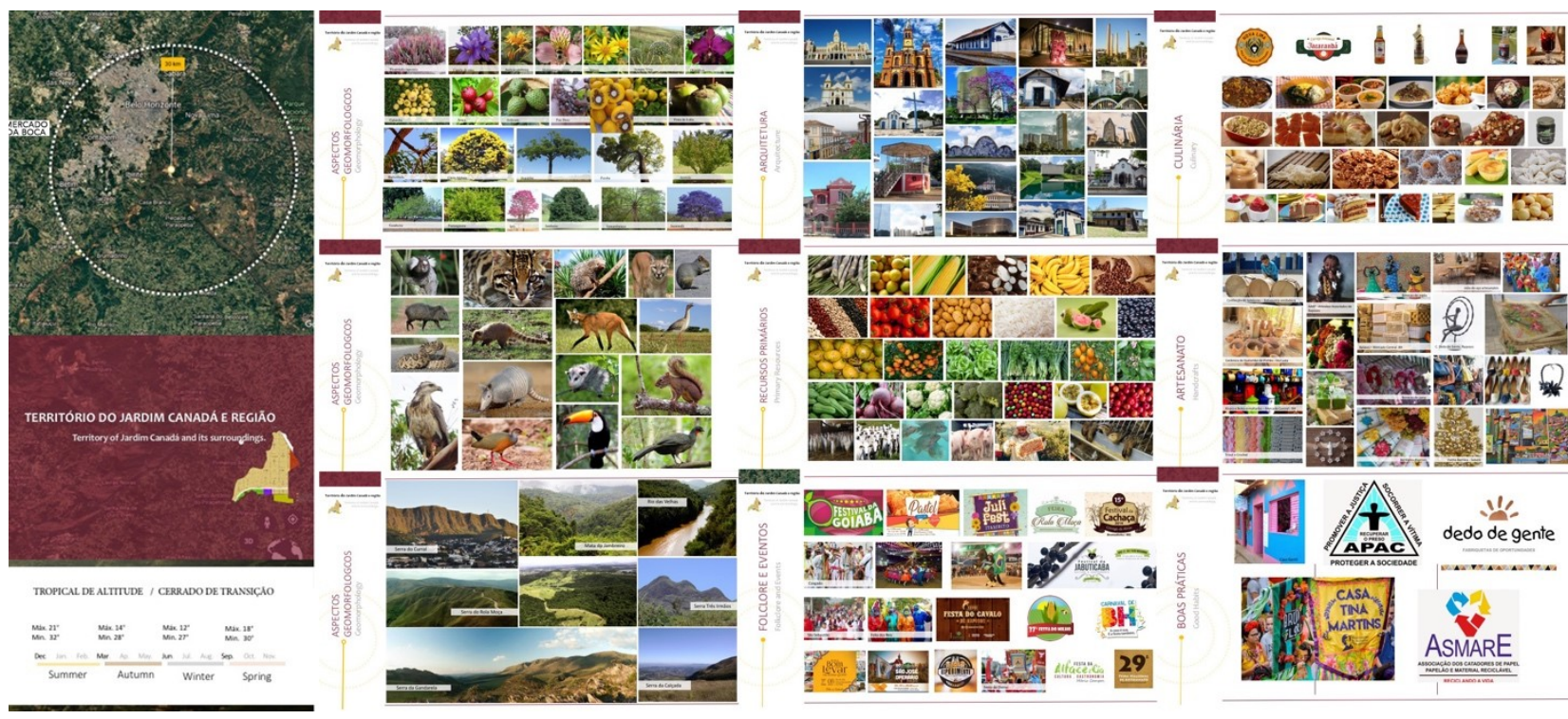

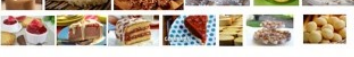

Fonte: Elaborado pelos pesquisadores

\subsection{Mercado da Boca - Abordagem Atual}

O 'Mercado da Boca' é um espaço gastronômico com aproximadamente 4 mil m², localizado na região metropolitana de Belo Horizonte, na cidade de Nova Lima, cerca de $35 \mathrm{~km}$ da capital. 0 espaço possui 19 restaurantes de renomados chefes de cozinha, atuantes em Belo Horizonte, que se aliaram com o intuito de oferecer à região uma gastronomia de alto nível a um custo acessível. 0 local também possui espaços próprios para comercialização de bebidas, espaço para crianças e eventos, distribuídos em dois pavimentos. A parte interna do MB possui mesas compartilhadas que ocupam a região central. Já os restaurantes, em estandes individuais, se localizam nas bordas. 0 espaço possui ainda uma área externa, na qual se encontram algumas mesas e uma pequena horta, situada na lateral de uma das escadas de acesso.

Durante os primeiros dias do workshop, o grupo de trabalho se informou sobre o funcionamento do estabelecimento, por meio de entrevistas livres com gestores e funcionários do espaço, observação in loco do negócio e visitas a alguns estabelecimentos na região. Nesse contexto, buscou-se informações quantitativas (como número clientes, número de refeições vendidas, quantidade de resíduos gerados, os input e output das atividades produtivas, entre outras) e qualitativas (percepção dos usuários, identidade, inserção no território da região, qualidade dos resíduos gerados, etc.). O objetivo era compreender o MB de maneira sistêmica, com seus fluxos de atividades, de produtos, de consumo, de materiais, de energia, e dos resíduos gerados, mesmo que brevemente, em função do tempo limitado da atividade.

A rápida visualização e compartilhamento das informações, sintetizadas em mapas visuais,

\footnotetext{
${ }^{20}$ O território abrangeu 16 cidades: Belo Horizonte, Contagem, Betim, Ribeirão das Neves, Santa Luzia, Sabará, Nova Lima, Raposos, Rio Acima, Itabirito, Moeda, São Joaquim de Bicas, Brumadinho, Mário Campos, Sarzedo e Ibirité, envolvendo então, o raio de $30 \mathrm{~km}$ a partir do 'Mercado da Boca'.
} 
favorece o entendimento da complexa teia de relações (ou falta delas) entre as partes envolvidas (FIGURA 2). Por meio desses, foram identificados os pontos de força (pontos 'positivos') e as alavancas para mudança (pontos 'negativos') do sistema atual (sistema linear).

Figura 2 - Mapas visuais dos atuais fluxos do MB, com seus 'pontos de força' e 'alavancas para mudança'
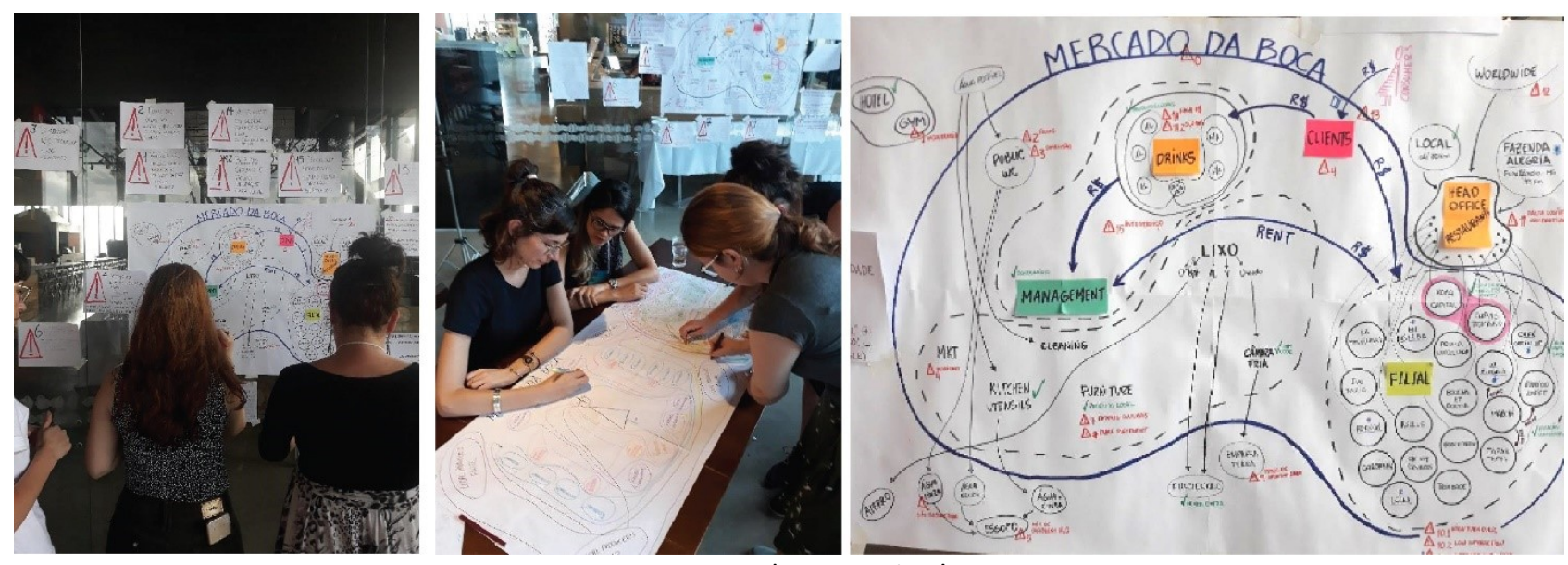

Fonte: Acervo dos pesquisadores

Vários esboços de mapas foram gerados com o intuito de exercitar a visão do todo e aperfeiçoar sua elaboração, pois trabalhar com a perspectiva da complexidade não é uma atividade trivial. A síntese final do estado atual ('estado da arte') pode ser observada por meio do Mapa Iconográfico a seguir (FIGURA 3).

Figura 3 - Mapa iconográfico do estado atual do Mercado da Boca (abordagem linear)

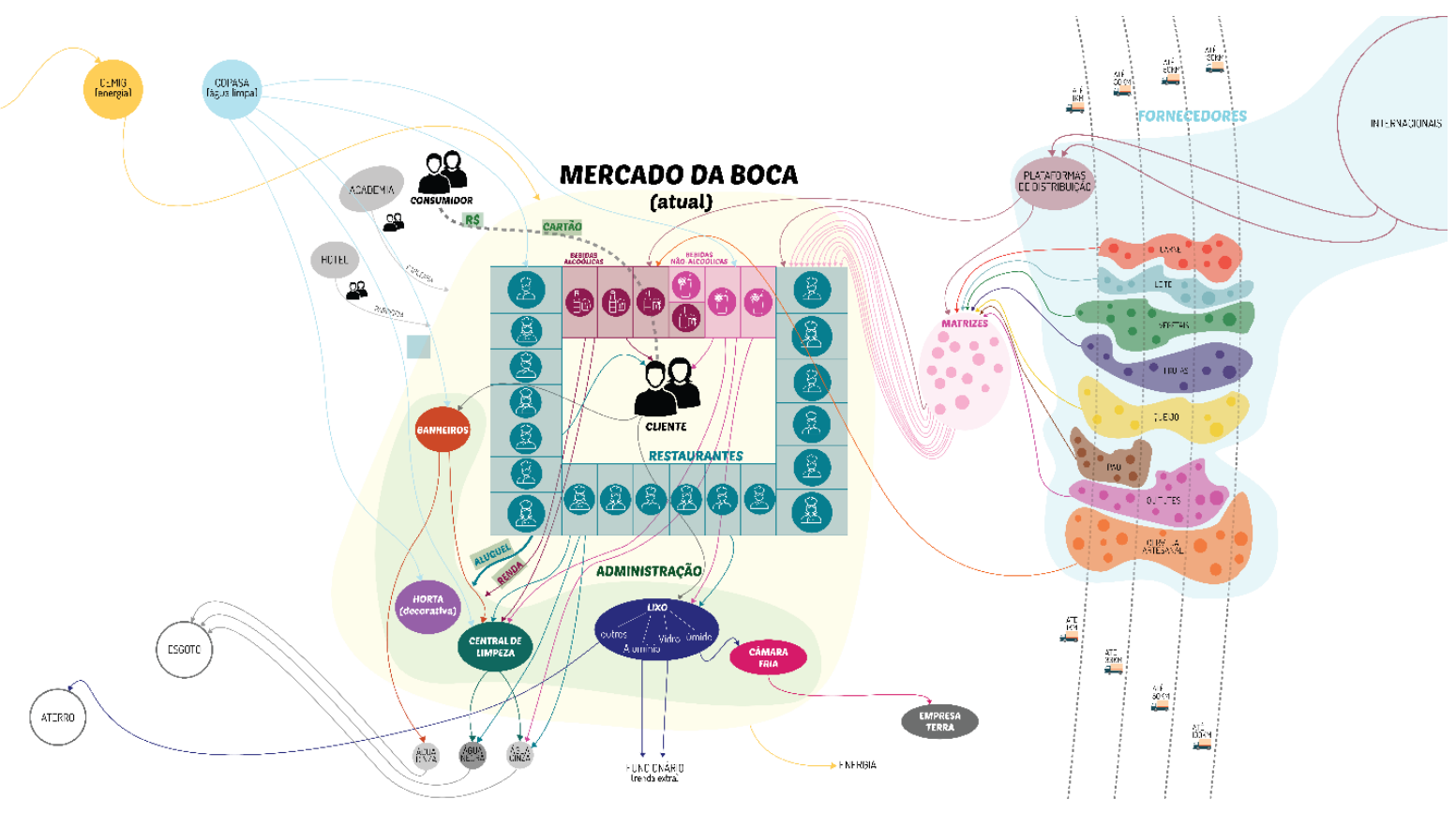

Fonte: Elaborado pelos pesquisadores

A reflexão acerca do estado atual do sistema permitiu a identificação dos diversos pontos de força e das alavancas para mudança. No Quadro 1, a seguir, podemos verificar as principais alavancas para mudança. 
Quadro 1 - Lista das principais alavancas para mudança levantadas

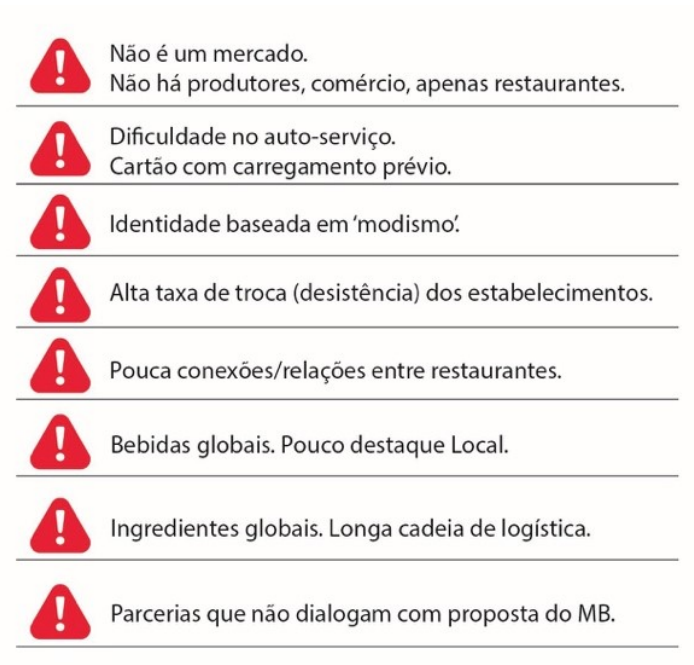

Louca relaçäo/conexão com o entorno do MB.
restaurante. 3 x ao dia.

Fonte: Elaborado pelos pesquisadores

Dentre as alavancas para mudança destacamos a desassociação da relação entre o 'Mercado da Boca' e o verdadeiro 'mercado' “[...] que é historicamente reconhecido como importante entreposto de circulação regional em relação ao qual se constroem representações coletivas de múltiplos significados" (SERVILHA; DOULA, 2009, p. 126). Neste contexto, acreditamos que um 'mercado' transcende a noção reducionista de comércio, pois esse expressa as manifestações culturais, locais, materiais e imateriais. Sendo assim, podemos inferir que o MB não pode ser considerado um 'mercado', pois o mesmo: i) é formado majoritariamente por restaurantes que oferecem cardápios 'internacionalizados'; ii) empregam diversos insumos importados para elaboração dos pratos, principalmente advindos dos países europeus; iii) possui poucas lojas que comercializam produtos; iv) não utiliza as redes de produtos e produtores do território; v) não valoriza a cultura local; ou seja, não propicia a experiência de um 'mercado'. Isso pôde ser comprovado ao se verificar que a percepção atual dos clientes é que o local se assemelha a uma 'praça de alimentação 'gourmetizada".

Ao longo do levantamento ficou evidenciado que a forma de pagamento empregada dificulta a espontaneidade da compra, prejudica a experiência e desestimula o consumo, visto que para usufruir do espaço e consumir, o cliente deve adquirir um cartão magnético e 'carregá-lo' com dinheiro para, somente então, ser atendido em um dos restaurantes ou lojas do MB. Essa précobrança provoca a sensação de que o usuário só é 'bem-vindo' por meio do consumo, caracterizando-se como uma relação estritamente comercial. Sendo assim, o estabelecimento perde a oportunidade de fomentar novas formas de experiência e construir uma relação mais próxima com seus clientes. Acreditamos que estas questões contribuíram para a queda de quase 50\% do movimento, quando comparado aos primeiros meses de lançamento, em 2018.

Por outro lado, destacamos como um dos pontos de força a oferta de pratos que exploram a culinária mineira. Ainda sim, o emprego de ingredientes, produtos e referências internacionais dificultam a construção de uma identidade do território, expõem longas cadeias de logística que contribuem para o agravamento das crises ambientais, sociais e econômicas.

\subsection{O Novo Mercado da Boca - Uma visão Sistêmica}


Atuar por meio da visão sistêmica, no âmbito do design, implica em projetar sistemas colocando o homem ${ }^{21}$ no centro do projeto, em criar relações entre os atores e a realidade produtiva em função de seu contexto ambiental, social, econômico e cultural ${ }^{22}$. Nessa perspectiva, a produção permite a criação de sistemas econômicos voltados para mercados específicos e contextualizados, que trafegam na contramão dos produtos globalizados, pois reconhece e valoriza os saber-fazer, os recursos, a identidade e a comunidade local.

Neste sentido, a análise concomitante dos processos, atividades e objetivos do negócio $\mathrm{MB}$, aliada às sínteses dos pontos de força e alavancas para mudança supracitadas, formaram a base de sustentação para o projeto sistêmico gerado durante o workshop (FIGURA 4). Este projeto, configurado em um mapa iconográfico, permite demonstrar visualmente as propostas de relações a serem instituídas. Estas viabilizam então, a emersão de atividades, postos de trabalho, produtos e serviços, além da amplificação significativa da renda do (e no) próprio território.

Figura 4 - Mapa iconográfico do 'Novo' Mercado da Boca (abordagem sistêmica)

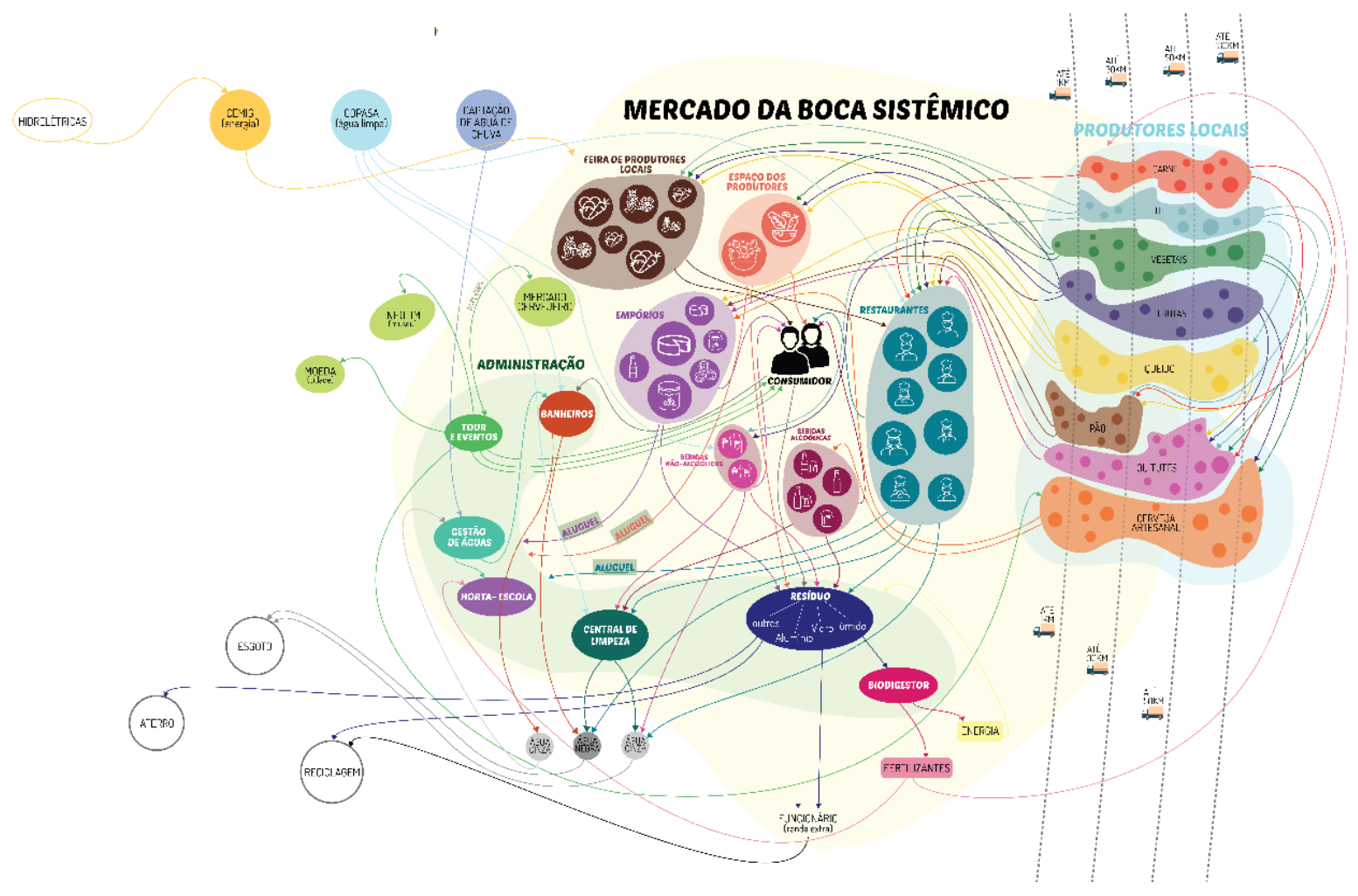

Fonte: Acervo dos pesquisadores

A organicidade encontrada neste mapa (FIGURA 4) se dá em função do entendimento de que as relações, na perspectiva sistêmica, são fluidas, e que as 'margens' das atividades podem sempre se expandir ou se deslocar para abrigar novas atividades necessárias e/ou convenientes.

Com a aplicação da metodologia do Design Sistêmico, o modelo atual de negócio foi transformado, principalmente, por meio do envolvimento de produtores e empreendimentos locais, que passaram a ser importantes parceiros estratégicos e atores do sistema. Essa abordagem favorece e reforça a tipologia e de um verdadeiro mercado.

Neste sentido, algumas questões foram consideradas fundamentais como, por exemplo, a reconfiguração dos estabelecimentos internos, que antes (abordagem linear) eram compostos

\footnotetext{
${ }^{21} \mathrm{O}$ homem relacionado ao seu próprio contexto ambiental, social, cultural e ético.

22 A cultura, acolhida como o quarto pilar da sustentabilidade na Rio+10, é para Boff (2015) uma dimensão fundamental para que, junto as outras três (social, ambiental e econômica), o desenvolvimento possa ser considerado sustentável.
} 
prioritariamente por restaurantes, e que depois (abordagem sistêmica) se transformaram por meio da inclusão de lojas que oferecem produtos do território, e de um espaço dedicado a comercialização direta com os produtores locais, inclusive com a oferta de produtos para os restaurantes. Esta aproximação pode encorajar a colaboração entre os mesmos, facilitando também a redução do desperdício, o racionamento da logística, o desenvolvimento sustentável do território, o melhoramento da qualidade dos produtos, a promoção do comércio justo, o resgate e reforço da identidade do território, e até mesmo a melhoria da percepção de valor pelo consumidor.

A região do $M B$ possui uma forte presença de fabricantes de cervejas artesanais, produto muito consumido e apreciado, principalmente, pelo público mineiro. Neste sentido, o projeto propõe aumentar sua variedade por meio de ingredientes locais, assim como pela oferta de turismo de experiência, por exemplo.

A proposta envolve ainda a promoção de feiras de produtores aos finais de semana, na área externa do MB. Seriam ofertados produtos alimentícios e artesanato local, envolvendo todos os agentes deste sistema: consumidores, produtores, comunidades locais, empreendedores, vendedores, estabelecimentos vizinhos, etc. Ainda no ambiente externo do MB propõe-se a ampliação da área da horta, de maneira que esta possa ser utilizada para a realização de cursos rápidos (sobre horta urbana, alimentação saudável e sustentabilidade) oferecidos às crianças da região e demais interessados.

Por meio da observação da localização geográfica do MB, identificou-se a vocação do mesmo para se transformar em um ponto de parada estratégica entre Belo Horizonte e cidades vizinhas, visto que possuem um rico potencial turístico como, por exemplo, Brumadinho (Museu de arte Inhotim), Moeda e Casa Branca (ecoturismo). Neste contexto, novas atividades e serviços podem ser projetados incluindo essas rotas, fortalecendo a experiência com a identidade mineira e produzindo alternativas de atração e geração de renda.

A partir de relatos dos usuários do MB concluiu-se seria necessário modificar o atual modelo de pagamento, relatado no item 4.3 desse artigo. No modelo proposto, o sistema foi substituído por comanda, com pagamento ao final, tornando a experiência mais fluída, natural e agradável.

O novo modelo apresenta ainda uma proposta para a utilização dos resíduos orgânicos de todos os estabelecimentos, por meio da construção de um biodigestor. Além das vantagens óbvias de sua implantação, destacamos: eliminação do consumo energético da câmara fria que acondiciona os resíduos orgânicos; extinção das emissões geradoras de impactos ambientais negativos, provenientes do seu transporte para o aterro sanitário; e produção de biofertilizantes para a horta do $\mathrm{MB}$, para a comunidade local e para os produtores deste sistema produtivo. Foi proposto também, a introdução do sistema de aproveitamento da água cinza gerada pelos estabelecimentos, e do sistema de captação das águas de chuva, que poderão ser utilizadas tanto nos banheiros, quanto na regadura da horta.

Importante ressaltar que todas as propostas apresentadas emergiram do próprio sistema, em função das especificidades do território, de seus atores, da sua cultura e dos seus recursos naturais. Como lembra Bistagnino, "[...] desfrutando a territorialidade dos recursos, aumentamos o desenvolvimento que privilegia a dimensão local e permite a criação de realidades autossuficientes do ponto de vista energético, produtivo e de aproveitamento" (BISTAGNINO, 2009, p. 21).

\section{Considerações Finais}

A quebra de paradigma, provocada pela abordagem sistêmica no âmbito projetual, foi o principal impacto relatado pelos participantes do workshop, visto que é uma maneira completamente diversa do nosso modus operandi. Houve certa dificuldade para transpor o pensamento linear e, de fato, esse processo ainda se encontra em construção ("loading..."). 
Contudo, os designers puderam compreender as potencialidades da aplicação da metodologia do Design Sistêmico.

Importante ressaltar que que o workshop teve um forte caráter acadêmico e teórico, certamente essencial para o aprendizado da metodologia e suas ferramentas. Porém, para que essa abordagem possa ser efetivamente implementada é necessário, além de capital de investimento e treinamento/aprimoramento da mão de obra local, que os atores do sistema formem uma 'rede'. Paula (2004) nos lembra que a força da 'rede' é dependente da multiplicidade dos pontos de conexão, i.e., quanto mais densa for a trama, quanto mais complexo for o tecido, maior será o fluxo de conhecimento e informação, o que resulta em mais participação democrática e mais controle social (PAULA, 2004).

Finalmente, conclui-se que o Design Sistêmico é uma metodologia coerente e apropriada para o enfrentamento dos desafios contemporâneos no âmbito de uma sociedade complexa e dinâmica, com múltiplas necessidades e carências.

\section{Agradecimentos}

Os autores agradecem ao Programa de Apoio a Eventos no País - PAEP | CAPES pelo apoio financeiro concedido para realização do Workshop 'Design Sistêmico Loading... - A construção de um modelo econômico-produtivo sustentável', no âmbito da Chamada Pública de Propostas de Eventos Científicos do Edital № 9/2018, e ao Programa de Pós-Graduação em Design da Universidade do Estado de Minas Gerais (PPGD | UEMG) pelo apoio e oportunidade.

\section{Referências}

BARAUNA, Débora; RAZERA, Dalton Luiz. Sustentabilidade, desenvolvimento e inovação no século 21: demandas para o design de materiais avançados. In: ARRUDA, A. J. V.; FERROLI, P. C. M.; LIBERLOTTO, L. I. (org.). Design, Artefatos e Sistema Sustentável - ([designcontexto]: Ensaios sobre Design, Cultura e Tecnologia). São Paulo: Blucher, 2018. p. 61-74.

BICOCCA, Miriam. Systemic approach applied to prisions. In: FORMIA, E. (org.) Innovation in design education: theory, research and processes to and from a Latin perspective. Torino: Umberto Allemandi \& C., 2012. p. 502-513.

BISTAGNINO, Luigi. Design sistêmico: uma abordagem interdisciplinar para a inovação. In: MORAES, D.; KRUCKEN, L. (org.). Cadernos de Estudos Avançados em Design: sustentabilidade. Barbacena: EdUEMG, 2009. cap. 1, p. 13-29.

BISTAGNINO, Luigi. Design sistêmico: Progettare la sostenibilità produttiva e ambientale. Bra: Slow Food, 2011. 310 p.

BOFF, Leonardo. Sustentabilidade: o que é - o que não é. Petrópolis: Vozes, 2015. 200 p.

BRANZI, Andrea. Moderdità debole e difusa: il mondo del progetto all'inizio del XXI secolo. Milão: Skira, 2006. $180 \mathrm{p}$.

CAPRA, Fritjof. A teia da vida: uma nova compreensão científica dos sistemas vivos. São Paulo: Cultrix, 2012. 256 p.

CAPRA, Fritjof. As conexões ocultas: ciência para uma vida sustentável. São Paulo: Cultrix, 2002. 296 p.

CAPRA, Fritjjof; LUISI, Pier Luigi. A visão sistêmica da vida: uma concepção unificada e suas implicações filosóficas, políticas, sociais e econômicas. São Paulo: Cultrix, 2014. 615 p.

CARDOSO, Rafael. Design para um mundo complexo. São Paulo: Ubu, 2016. 264 p. 
CELASCHI, Flaviano; FORMIA, Elena. Design cultures as models of biodiversity: design processes as agents of innovation and intercultural relations. Strategic Design Research Journal, São Leopoldo, v. 3, n. 1, p. 01-06, jan./abr. 2010. ISSN: 1984-2988. DOI: 10.4013/sdrj.2010.31.01. Disponível em: <http://revistas.unisinos.br/index.php/sdrj/article/view/4779>. Acesso em: 03 mar. 2019.

COMISSÃO MUNDIAL SOBRE O MEIO AMBIENTE E DESENVOLVIMENTO. Nosso futuro comum. Rio de Janeiro: Editora Fundação Getúlio Vargas, 1988. 430 p.

GALLIO, Veronica; MARCHIÒ, Andrea. New models of consumption: scenarios for sustainability. In: FORMIA, E. (org.) Innovation in design education: theory, research and processes to and from a Latin perspective. Torino: Umberto Allemandi \& C., 2012. p. 527-546.

IMBESI, L. Design comes Out of Industry: new critical approaches for design in the economy of postproduction. Crossing Talents! Cumulus Conference. Aalto University. Helsinki: [s.n.] 2012. p.36-43.

IRWIN, Terry. Transition design: a proposal for a new area of design practice, study, and research. Design and Culture, Londres, v. 7, n. 2, p. 229-246, set. 2015. ISSN: $1754-7083$ (online). DOI: 10.1080/17547075.2015.1051829.

Disponível

em:

<http://dx.doi.org/10.1080/17547075.2015.1051829>. Acesso em: 04 mar. 2019.

KRUCKEN, Lia. Competências para o design na sociedade contemporânea. In: MORAES, D.; KRUCKEN, L. (org.). Cadernos de Estudos Avançados em Design: Transversalidade. Belo Horizonte: Ed UEMG, 2008. p. 7-22.

MANZINI, Ezio; MERONI, Anna. Design em transformação. In: KRUCKEN, Lia. Design e Território: Valorização de identidades e produtos locais. São Paulo: Studio Nobel, 2009. 126 p.

MORAES, Dijon de. Design e complexidade. In: MORAES, D.; KRUCKEN, L. (org.). Cadernos de Estudos Avançados em Design: Transversalidade. Belo Horizonte: Ed UEMG, 2008. p. 7-22.

MORIN, Edgar. Introdução ao pensamento complexo. Tradução: Eliane Lisboa. Porto Alegre: Sulina, 2005. 120 p. Título original: Introduction à la pensée complexe.

PAULA, Juarez. Territórios, redes e desenvolvimento. In: Serviço Brasileiro de Apoio às Micro e Pequenas Empresas - SEBRAE. Territórios em movimento: cultura e identidade como estratégia de inserção competitiva. Brasília: Relume Dumará Editora, 2004. p. 72-84.

PAULI, Gunter. Blue economy: nuovo rapporto al Club di Roma - 10 anni, 100 innovazioni, 100 milioni di posti de lavoro. Milano: Edizioni Ambiente, 2010. 342 p.

SERVILHA, Mateus de Moraes; DOULA, Sheila Maria. O mercado como um lugar social: as contribuições de Braudel e Geertz para o estudo socioespacial de mercados municipais e feiras. Revista Faz Ciência, v. 11, n. 13, p. 123-142, jan./jun. 2009. ISSN: 1983-148X (versão eletrônica). Disponível em: <http://e-revista.unioeste.br/index.php/fazciencia/article/view/760>. Acesso em: 02 abr. 2019.

THACKARA, John. Plano B: o design e as alternativas viáveis em um mundo complexo. São Paulo: Saraiva: Versar, 2008. 300 p.

VASSÃO, Caio Adorno. Metadesign: ferramentas, estratégias e ética para a complexidade. São Paulo: Blucher, 2010. 130 p.

VIEIRA, Gabriel Bergmann Borges. Design e inovação: projeto orientado para o mercado e centrado no usuário. Convergências, Castelo Branco, v. 2, n. 4, p. 229-246, nov. 2009. Disponível em: <http://convergencias.esart.ipcb.pt/?p=article\&id=58>. Acesso em: 04 mar. 2019. 